\title{
O SILÊNCIO DE SÓCRATES NO PROÊMIO DO TIMEU
}

\author{
MARIA DA GRAÇA FERREIRA SCHALCHER* \\ Faculdade de Filosofia e Ciências Sociais \\ da Universidade Federal do Rio de Janeiro
}

\begin{abstract}
RESUMO: Neste texto, nós buscamos compreender as relaçôes entre mito e filosofia no pensamento de Platão, através do silêncio de Sócrates no diálogo Timeu.
\end{abstract}

PALAVRAS-CHAVE: silêncio; mito; filosofia; memória; estrangeiro; hospitalidade.

Para quem lê e relê, cada diálogo é um fragmento total: total, já que não representa nem uma parte nem um momento da doutrina, mas um exercício; fragmento, porque para quem lê, cada palavra é impregnada pelo trabalho dialético efetuado por cada um dos outros Diálogos.

(Dixsaut, 1985, p. 31)

No Livro IV das Leis, 722a-d, vemos um dos seus personagens, o ateniense, lembrar aos outros presentes, que desde que começaram a discorrer, a aurora dera lugar ao meio-dia e que tudo que fora dito até então havia constituído apenas um proêmio, no caso um "longo proêmio". Sem considerá-lo vão, diz que todo discurso, tudo o que confere um papel à voz, comporta um proêmio onde se dão os passos preliminares de um encaminhamento metódico, útil ao texto que se prepara, assim como o prelúdio, na música, introduz o seu tema. Um elemento persuasivo (encantatório?) que contribui nessa obra, para a dócil aceitação das prescrições do legislador ${ }^{1}$.

A partir dessa colocação, interrogar um silêncio, o silêncio de Sócrates tal como se tece no proêmio do diálogo Timeu, cuja exposição configura um discurso mítico, nos pareceu um caminho possível para a compreensão da relação entre mito e filosofia no pensamento de Platão ${ }^{2}$, objeto dessa palestra. 
Tal interrogação, repete a experiência da admiração contida na pergunta

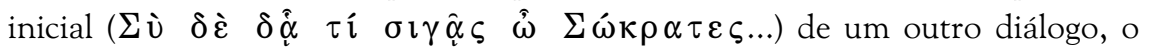
Hipias Menor, que gostaríamos também de pensar ter sido a "primeira frase do primeiro diálogo escrito por Platão" (Dixsaut, 1985, p. 88), e que nos mostra um Sócrates emudecido frente à eloquência de Hípias que todos os outros presentes se apressam a elogiar. Estaria paralisado pela extensão da sua sabedoria ou por incapacidade de refutá-lo? Ou muito mais pela constatação da ausência de um liame ontológico para que um verdadeiro diálogo pudesse se estabelecer?

Se compararmos esses dois momentos, veremos que, tanto no Hipias Menor como no Timeu, o silêncio de Sócrates surge no contexto do elogio, ligado porém a uma impossibilidade, justamente a de elogiar seja um discurso, seja uma cidade e os homens que a integram. Havendo entre ambos, porém, uma evidente dissimetria, já que a admiração causada por esse silêncio, tão marcante no Hípias Menor, 363a, tal como se expressa na veemente interrogação de Eudicos: "Por que te calas, Sócrates, após Hípias ter feito tão bela exposição e por que não te juntas a nós para o aprovar? Ou se achas que não falou bem por que não o criticas?. Ainda mais que nos achamos entre nós, entre pessoas que pretendem se interessar vivamente pelos entretenimentos filosóficos?", não se faz presente no Timeu. E também porque no primeiro, que pertence ao grupo do que se convencionou denominar "diálogos socráticos", tanto a "impotência" como o silêncio são momentâneos e logo se transmutarão em interrogação, instaurando a partir de e suscitado por esse primeiro espanto e por essa primeira pausa, o discurso filosófico. Já no segundo, o silêncio socrático aparece como condição para o surgimento e legitimação do discurso verossímel de um mito. O que nos permite pensá-lo em ambos, não apenas relacionado à pretensa modéstia de Sócrates, mesmo levando em conta a dimensão irônica dessa modéstia, mas sim à condição presente no Fedro, 276a, da existência de um discurso que sendo capaz de "defender a si mesmo", já que é acompanhado de sabedoria, "sabe tão bem falar, como calar" diante do que é preciso ${ }^{3}$, o que caracteriza o discurso dialético.

O diálogo Timeu tem início sem maiores preliminares. Um, dois, três, enumera Sócrates. E é esse contar/discriminar, papel atribuído na República, VII, 522c, à "modesta ciência que permite distinguir o um do dois e do três", ou seja, a "ciência do número e do cálculo", que lhe permite constatar uma ausência. Mas onde está, meu caro Timeu, o quarto, que ontem esteve conosco acedendo a meu convite, e que hoje, como meu anfitrião se ausenta? Sobre a existência e a identidade desse personagem as hipóteses se multiplicam ${ }^{4}$. Mas o que nos interessa aqui, muito mais que identificar um ausente é pensar o sentido, ou melhor, um sentido 
possível para essa ausência, que na opinião de Timeu deve ser atribuída a uma inesperada fraqueza, $\dot{\alpha} \sigma \theta \dot{\varepsilon} v \varepsilon \imath \alpha$, porque só um motivo muito forte poderia explicála. E que deverá, como reivindica Sócrates, ser compensada pelos presentes, para que não se quebrem as regras e não se perca o valor da hospitalidade, aceita e retribuída, não apenas a pessoas, mas também a discursos, inserindo a filosofia num contexto de diálogo e desdobrando essa ausência num silêncio que se harmoniza, como num acorde, com o silêncio de Sócrates.

Suprir essa ausência irá requerer não apenas o empenho e a boa vontade dos presentes, que se apressam aliás a hipotecá-los, mas também e principalmente, um redobrado esforço de rememoração capaz de preservar a ligação entre tempos, o ontem e o hoje, e discursos, o de Sócrates, o do ausente e o de seus interlocutores, enfatizando a dimensão filosófica da memória e ao mesmo tempo testando neles essa capacidade. Assim, nós o vemos perguntar se todos se recordam das questões tratadas na véspera. Timeu pensa que sim. Mas temendo alguma possível omissão, evoca o testemunho de Sócrates e propõe prudentemente uma recapitulação no seio da qual emerge, a partir da interrogação "sobre a melhor forma de governo" e sobre que "espécie de homem deverá exercê-lo", o tema recorrente da cidade justa e reta, revelando enfim o tema do entretenimento anterior (Tim. 17c: $\lambda o ́ \gamma \omega \nu \pi \varepsilon \rho \grave{\imath} \pi \circ \lambda \imath \tau \varepsilon \hat{\imath} \alpha \varsigma$ ), e reintroduzindo a questão da justiça.

No final dessa recapitulação, Sócrates insiste em perguntar se ela foi completa ou se é preciso lamentar alguma falta. A resposta de Timeu que a considera satisfatória é fundamental para a compreensão do papel exercido nesse diálogo pelo silêncio de Sócrates, permitindo levantar uma hipótese sobre a ausência por ele lamentada e tecer entre ambos, silêncio e ausência, um estreito e indissolúvel liame. Compreensão e hipótese que se constróem ainda, significativamente, sob o signo de uma falta, já que não é possível identificar com segurança o discurso aquí evocado, nem mesmo saber se ele foi um dia escrito ${ }^{5}$ ou constitui apenas uma ficção platônica.

No entanto, seja porque apesar da segura resposta de Timeu $u^{6}$, algo tenha sido desafiadoramente omitido por Sócrates, caso o discurso evocado corresponda ao da República, seja porque a recapitulação tenha sido de fato fiel e completa e todos tenham se contentado com o modo pelo qual a questão fora tratada na véspera, ressoa para nós, afeitos a um outro $\lambda o ́ \gamma o \zeta$, o eco do que falta: A educação do filósofo, o seu papel na cidade, ou seja, no limite, a filosofia. $\mathrm{O}$ que faz com que a República continue sendo o referencial de nossa análise, já que essa recapitulação nos deixa no limiar da "terceira vaga", a mais alta e a mais difícil de 
ser vencida, onde se consumaria a união entre o poder político e a filosofia (Rep.

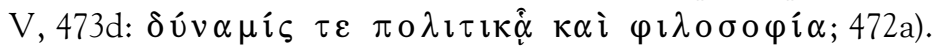

Ora, uma dimensão dessa dupla falta, a ausência visível de um conviva e a ausência invisível e inaudível de um discurso, talvez possa ser compensada por Timeu, por Crítias e por Hermócrates. Afinal, como nos mostra Sócrates, eles pertencem à espécie dos que, pela sua natureza e educação, participam tanto da

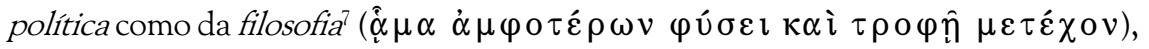
o que deveria capacitá-los a cumprir o desejo por ele manifestado de dotar de vida e movimento a cidade cujo plano gerador fora traçado na véspera pelo seu discurso, mas que permanece inerte como um belo animal pintado num quadro

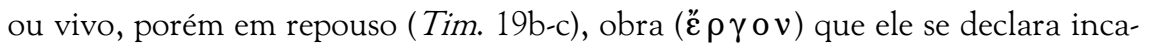
paz de cumprir. É justamente essa "incapacidade" que motiva sua proposta de calar-se, entregando-se à hospitalidade do discurso de seus convivas (Tim. 20c:

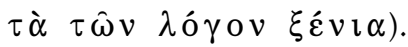

Através da imagem que ilustra seu desejo, Sócrates nos faz passar da dimensão da geometria, a superfície (o animal pintado num quadro), para à da estereometria, pela introdução do volume e portanto do corpo (o animal como ser natural) e à da astronomia, pela introdução do movimento e das leis de sua possível e desejável ordenação, reintroduzindo sutilmente e em ligação com a primeira frase do proêmio, a sequência das ciências requeridas para a educação do filósofo na República, mas revelando contudo em relação a ela, uma inversão e uma falta. De um lado porque no Timeu essas ciências não são explicitamente mencionadas e de outro, porque em vez de ser escalonadas num movimento de ascensão coroado pela dialética, configuram um movimento de descida em direção à história (a ação, a guerra), que na imagética da Linha Dividida (Rep. VI, 509d-511e) pertence à dimensão do sensível / visível sobre a qual não há ciência.

Aceitando porém o desafio da ironia e admitindo uma imprecisão propositada no uso platônico dos termos filosofia e filósofo atribuídos aos interlocutores de Sócrates, aceitando também como consequência possibilidades múltiplas de buscar e de acolher múltiplas figuras de $\sigma \circ \varphi \hat{i} \alpha$, seremos capazes de perceber que uma estranha ressonância persiste apesar e por causa do silêncio de Sócrates. A transição operada nesse momento entre os passos do proêmio, que num só movimento permitem a (re)introdução e a (re)exclusão desses personagens e de seus discursos, é de tal modo sutil que não provoca em seus ouvintes nem espanto nem protesto. Ora, se essa presença é de certo modo necessária, já que o discurso do elogio, tanto na sua dimensão retórica como na sua dimensão poética, constituem o domínio desses personagens, a naturalidade com que 
Sócrates compartilha com eles sua "incapacidade" para elogiar essa cidade e seus homens, é estranha e inesperada.

Acompanhando o argumento socrático nós o ouvimos dizer, referindose aos poetas, tanto aos antigos como aos atuais, que "a espécie dos imitadores" sabe imitar facilmente um mundo semelhante àquele em que foi educada. Mas acha difícil imitar, seja em ações seja em palavras, o que não lhes é familiar. Assim, mesmo que possa ser coroada como foi outrora (Rep. II, 398a), não teria um papel a cumprir numa cidade que como ele deseja, possa mostrar-se através de suas ações, tanto na paz como na guerra, digna da instrução e educação de seus cidadãos. Pelo mesmo argumento, ligeiramente modificado, a errante e desenraizada espécie dos sofistas será também excluída (Tim. 19d-e).

Representantes de uma tradição exangue ou proponentes de uma nova $\sigma o \varphi \hat{i} \alpha$, são ambos produtores de simulacros, que pela ausência de um critério seguro capaz de fundamentar na diferença entre o justo e o injusto, a diferença entre o elogio e a desaprovação, relativizam o modelo da ação justa, revelandose estrangeiros tanto à cidade modelo como à cidade que dele deveria nascer. Assim, ao compartilhar com poetas e sofistas uma certa "impotência", se Sócrates aponta para um enigmática semelhança, já que através de sua vida se mostra, se diz e é dito, $\xi \dot{\varepsilon} \vee$ o $\varsigma^{8}$, aponta contudo para uma importante diferença, desafiando-nos e aos seus convivas a percebê-la e a compreender em que dimensão essa diferença se institui. $\mathrm{Na}$ aceitação e resolução desse desafio/enigma, está portanto implicada a dupla possibilidade tanto do acolhimento dos discursos de Timeu, de Crítias e de Hermócrates, como do estabelecimento de uma diferença entre esses discursos e o de Sócrates, pois eles imitam também a tradição em que foram educados, seja essa Locres, Atenas ou Siracusa ${ }^{9}$, sendo também estrangeiros à cidade modelo. $\mathrm{O}$ que legitimaria então a sua não exclusão desse entretenimento?

Essa possibilidade é comandada, a nosso ver, por toda a urdidura do proêmio que estabelecendo sutis mudanças de registro e superposições inusitadas de tempos, discursos e lugares, nos reconduz à Caverna ausente/presente no jogo de luz e sombras entre saber e não saber onde se configuram, se substituem e/ou se confrontam, falsos saberes tomados como saber; saberes parciais confundidos com o saber; não saberes que pensam que sabem; e um saber cujo portador estranha e recusa o nome de sábio. Instigante recusa, desdobrada em inciência, que engendra e alimenta um desejo permanente e uma busca incessante de testar em si mesmo e por si mesmo a dimensão aberta pela interrogação, ou seja, a filosofia. 
Nesse jogo que comandará toda a sequência do diálogo, uma vez repetida e relegitimada a exclusão dos discursos da poesia e da sofística, podem se legitimar, confrontar e relacionar agora, dois outros tipos de discurso. O de Sócrates, que tendo falado ontem, hoje se cala, mas cuja voz continua ressoando para os que tenham acuidade de audição e boa memória e não considerem o silêncio como o contrário absoluto da fala nem o invisível como o contrário absoluto do visível, e o de seus interlocutores, cuja educação, no plano da história, parece ser a melhor e a mais completa possível.

Se nos reportarmos novamente à República, veremos que nela Sócrates

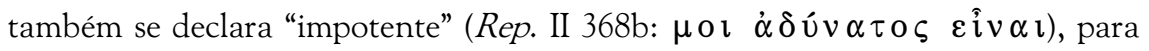
defender a justiça. $O$ que o leva a infletir a discussão dessa questão para o âmbito da visão, através da imagem dos dois textos escritos, um em letras minúculas e outro em letras maiúsculas, cujo longo desenvolvimento, passando pela tarefa de imaginar a formação de uma cidade, vai culminar no Livro VII, com a contemplação do bem.

Vemos agora a pretensa e enigmática "incapacidade" de Sócrates, que determina o seu silêncio, surgir como a medida de uma diferença presente ainda que sob a forma de uma ausência. Como ontem no $\tau$ ó $\pi$ o $\varsigma$ do inteligível, o percurso pelo modelo era necessário, Sócrates falava e a filosofia se fazia presente, hoje, a retração da filosofia simbolizada numa ausência, num silêncio e num possível esquecimento por parte dos presentes, o é também. Mas, no seio da hospitalidade que pressupõe a $\varphi \imath \lambda i ́ \alpha$, será essa retração que irá presidir, ainda filosoficamente, através de uma presença invisível, a tentativa de redução da distância entre o inteligível e o sensível, na busca de uma dimensão ao mesmo tempo receptáculo e matriz, que permita instaurar entre ambos a possibilidade de uma participação ontológico-discursiva, abrindo o caminho para o discurso verossímel do Timeu. Na ordem desejável dos discursos ${ }^{10}$, será ele, o que mais se aprofundou nas questões relativas à natureza do todo, que deverá falar primeiro, a fim de que, partindo "do nascimento do mundo", possa chegar "à natureza do homem" (Tim. 27a) e à dimensão da cidade.

Na seqüência do entretenimento, porém, veremos essa ordem ser prévia e simetricamente invertida, já que é Hermócrates que primeiro, embora brevemente, fala (Tim. 20c-d). E ele o faz para lembrar que, se a questão é dotar de vida e movimento o modelo, haveria talvez um percurso mais curto que passaria pela própria história, pois parece ter havido em tempos muito recuados, uma cidade assim. Passando a palavra a Crítias para que esse relate "uma história 


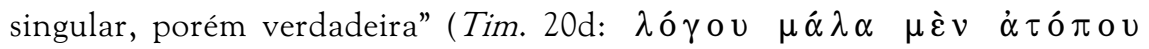
$\pi \alpha \nu \tau \hat{\alpha} \pi \alpha \sigma i$ $\gamma \varepsilon \mu \hat{\alpha} \nu \dot{\alpha} \lambda \eta \theta o v \varsigma)$, suscita uma nova superposição de tempos, lugares e discursos, como signo de uma impossibilidade de uma transposição imediata do modelo à história, o que realimentará a relação com o mito.

Pois a verdade do relato de Crítias, embora emerja de um exercício de memória na dimensão do que chamaríamos "tempo histórico", é somente despertada pelo eco de uma semelhança entre o discurso socrático sobre a cidade paradigma e uma narrativa quase esquecida, ouvida quando bem criança, de um antepassado de quem herdou o nome e o discurso, que por sua vez a ouvira de Solon. A condição e o fundamento do resgate dessa "antiga tradição" se encontra

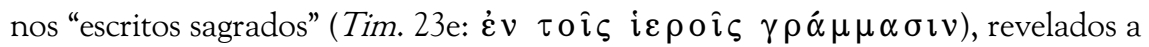
Solon por um sacerdote egípcio. Se é certo que a ausência de um registro faz com que os gregos ignorem, pelo efeito do tempo, das catástrofes e da morte dos que a viveram, a "existência histórica" dessa cidade ancestral, também é certo que ao fazê-los recuperar essa tradição através de um relato oral, que vai de Sais a Atenas, dos documentos imemoriais ao sacerdote que os revela, ainda oralmente, a Solon, já que a leitura dos arquivos fica para sempre adiada e deste aos antepassados de Crítias, que por sua vez a fazem chegar até ele, Platão nos coloca no contexto da memória, como única instância capaz de vencer uma descontinuidade de tempo e de localização não só entre as duas Atenas mas entre o paradigma e sua perdida realização, fazendo-a transcender a dimensão histórica.

Portanto, mesmo que se aceite a suposição de Crítias sobre uma correspondência entre a cidade construída através do discurso de Sócrates e a Atenas histórico-mítica de outrora e entre os homens da cidade modelo e os longínquos ancestrais dos atenienses de hoje, seria ainda necessário, frente a essa descontinuidade irredutível, fazê-los renascer, tornando-os visíveis e tangíveis. Crítias não poderá ser o herdeiro direto das palavras de Sócrates, apesar da aparente similitude de seus discursos e de seus desejos. Pois antes de ordenar a cidade e educar os homens inserindo-os na ordem política, é preciso primeiro fazê-los nascer na ordem natural e racional, remontando à origem do todo. O que exigirá a restauração da sequência dos discursos, pela necessidade de fundamentar a história na inteligibilidade ontológica do tempo e do movimento, sem o que a possível transposição do modelo se perderia na destruição, tal como parece já ter acontecido à cidade ancestral, e na desordem em que mergulha Atenas de agora. O $\pi \varepsilon \rho \grave{i} \varphi u ́ \sigma \varepsilon \omega \varsigma$ deve assim preceder o $\pi \varepsilon \rho \grave{\imath} \pi \sigma \lambda \imath \tau \varepsilon \hat{\imath} \alpha \varsigma$.

Será essa a tarefa de Timeu, o que implicará em repensar a relação desejável entre "o ser eterno", que nunca nasce e o que nasce sempre e não é jamais, a 
partir da hipótese da forma como paradigma ${ }^{11}$, já que é pela contemplação e pela imitação do modelo que o demiurgo, persuadindo a necessidade e a desordem a aceitarem a ordem do $\lambda$ ó $\gamma o \zeta$, plasma racional e artesanalmente a alma do mundo e a alma do homem, fazendo-os participar da instância do divino e da imortalidade, tarefa herdada no plano do corpóreo e perecível pelos rebentos por ele gerados, e pelos futuros planejadores de cidades, eles também demiurgos ${ }^{12}$.

Significativamente, a retomada dessa hipótese ${ }^{13}$, embora já pertença ao discurso de Timeu, se dá ainda no âmbito do proêmio, sob a égide de Sócrates, constituindo nele uma espécie de desdobramento. E só após serem distinguidas as instâncias do paradigma e da cópia e definidos os raciocínios a elas correspondentes, Sócrates se calará, exortando Timeu a nos dar enfim, após esse proêmio / prelúdio, seu texto/tema.

Nesse texto será retomado o desafio resultante das aporias presentes no diálogo Parmênides, $135 \mathrm{c}^{14}$, recolocando em questão a possibilidade da participação do sensível ao inteligível. Não se trata mais de pensar, como no diálogo $O$ Sofista, a questão da relação entre as idéias segundo as regras definidas pela dialética, o que já permitiu a Platão fundar ontologicamente a possibilidade do discurso e a distinção entre o discurso falso e o discurso verdadeiro, entre o sofista e o filósofo. Trata-se agora de fundar num só movimento uma semelhança e uma diferenciação ontológicas no seio do discurso verdadeiro, desdobrando-o num discurso verossímel. O que o leva a retomar a questão do estatuto da cópia, diferenciada pelas duas miméticas (Sof. 267d-e) da instabilidade irredutível do simulacro e pelas duas metréticas (Pol. 283d-287a) da disseminação anárquica dos incompossíveis, resgatando-a como um misto ( $\mu \varepsilon \tau \alpha \xi \tilde{u})$, que atestando a presença do invisível / inteligível no sensível requer a instauração de um discurso a ela adequado. Tal discurso, mítico porque se institui e se instala entre as duas dimensões, não comporta, como nos diz Timeu, exatidão, comprovação, demonstração (Tim. 29c-d). Pois pressupõe a crença num liame invisível capaz de viabilizar pela potência do raciocínio verossímel, a possibilidade de uma ordem proporcional e justa, tanto no nível do mundo, como no da alma e da cidade.

Somente no seio dessa possibilidade, Crítias poderá herdar os homens nascidos pelo discurso de Timeu e educados por Sócrates, para inserí-los enfim na ordem da cidade histórica. O que dará lugar a um novo tipo de discurso que, versando agora sobre assuntos mortais e humanos, será ao mesmo tempo difícil e impreciso (Crit. 107d-e) $)^{15}$. Ora, como nos mostra um outro longo proêmio, dessa vez o da República ${ }^{16}$, veremos que em termos de herança, as possibilidades de conservá-la, acrescê-la ou dissipá-la (Rep. I, 330a-b) se inscrevem tanto na 
dimensão da $\varphi$ v́ $\iota \varsigma$ como na da história. Da herança recebida por Crítias, o que se conservou, o que se ganhou, o que se perdeu?

O inacabamento do diálogo que porta seu nome com a consequente ausência da Atenas histórica e a inexistência do que seria o diálogo Hermócrates, fazendo com que o único verdadeiro interlocutor de Sócrates nesse entretenimento seja de fato Timeu, vem marcar, mais uma vez, a ausência de um discurso, dessa vez o discurso histórico-político, cujos porta-vozes seriam justamente Crítias e Hermócrates. Mas como em Platão nada se diz em vão, pois o que está sempre em questão é a filosofia, essa ausência, perpetuando a estranha indiferença da República, V, 472d, a respeito da existência ou não de uma cidade reta, boa e justa, parece confirmar um pretenso idealismo platônico.

Estranho idealismo que, reafirmando e preservando um desejo e uma possibilidade, faz ecoar também essa fala ausente, ao manter um entrelaçamento entre o discurso verdadeiro e o discurso verossímel, entre filosofia e mito. Assim, mesmo que, reafirmando o princípio de que "a ação tenha menos aderência à verdade que o discurso" (Rep. V, 473a), Sócrates não consiga mostrar perfeitamente realizado na prática tudo aquilo que construiu com suas palavras, e mesmo que Timeu não possa provar que na gênese do mundo tudo tenha se passado conforme seu relato, essses discursos, pelo seu poder persuasivo, fundamentados na crença da existência do bem e na possibilidade do homem participar, pela sua alma, do imortal e do divino, engendrarão uma ação que, tornando visível na alma e na cidade a invisível presença da $\varphi \rho o ́ v \eta \sigma \imath \varsigma$, será capaz de gerar a "vida mista", tal como se mostra no Filebo, 22a-b, como "a melhor possível", e a instituição das Leis.

Concluindo, podemos pensar o silêncio de Sócrates, tal como se mostra no proêmio do Timeu, como a metáfora de um silêncio imposto por um certo tipo de cidade a um certo tipo de discurso, cuja situação limite seria a condenação de Sócrates pelo tribunal de Atenas, mas que a antecede e se repete cotidianamente nas tensas e difíceis relações entre o filósofo e a cidade, o que o caracteriza como $\xi \dot{\varepsilon} \nu$ o $\varsigma$ e como $\ddot{\alpha} \tau$ o $\pi$ o $\varsigma$.

Se aceitarmos porém que a conduta de Atenas, que culminou na condenação e morte de Sócrates, engendrou a escrita filosófica de Platão, veremos que tal metáfora só é parcialmente verdadeira. Pois sendo capaz de transformar a pena em escolha, talvez a única possível, o filósofo, a partir de uma certa forma de silêncio, instituirá, na interseção de todos os saberes e de todos os poderes, uma diferença que lhe permite definir e assumir o único papel que ele pode exercer no nível da história. Assim, longe de repetir o gesto de Atenas em relação à filosofia e pretender calar o rumor presente nas cidades, onde proliferam 
todas as formas de discurso, a filosofia faz deles seus "outros", revelando-se como pura trancendência, sem máscara ôntica, capaz porém de assumir e transgredir todas elas, sem nelas se esgotar e sem esgotar também a potência infinita de um diálogo que põe cotidianamente em causa o aqui e o agora das respostas aparentemente inquestionáveis e supostamente definitivas.

Diferenciando-se do discurso dos falsos imitadores, mas sem nenhuma garantia tangível de sua verdade, escapando a fluidez errática da $\delta$ ó $\xi \alpha$ sem se deixar porém cristalizar em sistema, rompendo as amarras da exatidão do discurso científico-técnico sem renunciar ao rigor que sempre a coloca à prova, a filosofia encetará uma relação de recíproca $\xi \varepsilon v i \alpha$ com o mito, tecendo a partir de um princípio invisível a invisível diferença que lhe permite dizer, ainda que por intermédio de um silêncio, o que não pode ser aprisionado e dito por nenhum discurso.

\section{Notas}

* Professora Doutora do Departamento de Filosofia da Faculdade de Filosofia e Ciências Humanas da UFRJ.

1 Aristóteles retoma essa colocação na Retórica, IV, 1414b, comparando o proêmio ao prólogo e ao prelúdio, e mostrando que sendo o começo do discurso ( $\dot{\varepsilon} \sigma \tau \grave{\imath} v \dot{\alpha} \rho \chi \dot{\alpha}$ $\lambda o ́ \gamma o u)$, propiciam a abertura de um caminho, ó $\delta$ o $\pi$ oí $\rceil \imath \iota$, não só para a introdução de um tema, mas para portá-lo e conduzi-lo a seu $\tau \varepsilon \dot{\varepsilon} \lambda$ o $\varsigma$.

2 A questão da presença do mito no pensamento de Platão vem sendo discutida desde a antiguidade. Algumas interpretaçōes modernas já são consideradas clássicas, como a obra de P. Frutiger, Les Mythes de Platon. Para não multiplicar citações, remetemos à controvérsia recente entre M. Detienne, L'Invention de la Mythologie e L. Brisson, Platon les Mots et le Mythes, bem como à breve mas enriquecedora análise dessa questão e dessa polêmica feita por L. Couloubaritsis (Couloubaritsis, 1986, p. 45).

3 Não pretendemos abarcar nesse trabalho toda a extensão semântico-filosófica em que o silêncio aparece nos diálogos platônicos, nem a variada gama de interpretações que suscitou, mas trabalhar apenas a dimensão que queremos enfatizar.

4 Tais hipóteses se referem aos mais variados personagens, entre os quais o próprio Platão ou alguém a quem a Teoria das Idéias fosse familiar.

5 A partir das semelhanças assinaladas entre esses passos do Timeu e certos passos da República, discute-se ainda hoje, apesar de assinaladas também as dissemelhanças, se o resumo feito por Sócrates se refere de fato à esse diálogo ou se o entretenimento referido no Timeu é uma livre criação de Platão, sem correspondência imediata com nenhum diálogo por ele escrito. Para nossa proposta, resolver essa questão é irrelevante. 
6 É preciso enfatizar que nesse momento é Timeu que fala e não Sócrates ou, muito menos, Platão.

7 Notamos que Sócrates se refere de modo depreciativo no Eutidemo, 305c-e, a essa mistura de filósofo e político.

8 É assim que Sócrates se mostra e se diz, por exemplo, no tribunal ( $A p$. 17a), em relação ao discurso dos seus acusadores; e é assim que é visto por Fedro, no diálogo homônimo, (320c-d).

9 Locres é uma cidade conhecida em toda Grécia pela sua "eunomia”. O que nos dá uma pista para a possível diferença entre a educação e o discurso de Timeu, e os de Crítias e Hermócrates.

10 Tal como é sugerida por Sócrates (Tim. 20a-b) e estabelecida por Crítias (Tim. 27a-b). Embora nesse momento Hermócrates não seja mencionado, ele novamente o será, quando Sócrates, já no Crítias, 108a, a ele se referir como o terceiro orador.

11 Hipótese já presente no Crátilo, 389a-b, e na República, 596b, e que reaparecerá nas Leis, 903e-904a.

12 O uso platônico do termo demiurgo possui uma extensão semântica abrangente, que inclui tanto a artesania como a magistratura.

13. O Timeu se mostra um elemento perturbador para os que aceitam a existência de uma evolução no pensamento de Platão que o teria levado a abandonar a hipótese das formas. Para um quadro dessa questão, no âmbito das interpretações modernas e contermporâneas, remetemos à obra de L. Brisson (Brisson, 1974, p. 165-75).

14 Ao pensar nas consequências que resultariam do fato de negar para cada realidade a existência de uma forma, Parmênides mostra que tal posição, se levada às últimas conseqûencias, aniquilaria a própria dialética. E pergunta: "o que farás então, da filosofia?” Nesse momento Sócrates admite não encontrar nenhuma resposta.

15 Para Crítias, a diferença entre seu discurso e o de Timeu reside no fato de que se trata agora de bem imitar coisas mortais e humans ( $\tau \grave{\alpha} \delta \grave{\varepsilon} \quad \theta v \eta \tau \grave{\alpha} \quad \kappa \alpha \grave{\imath} \dot{\alpha} \nu \theta \rho \omega \dot{\pi} \iota v \alpha)$ e portanto visíveis, que embora também não comportem exatidão, permitem comparar o modelo à cópia.

16 É assim que Sócrates se refere, no início do Livro II, 357a, às discussões sobre a justiça presentes no Livro I.

\section{REFERÊNCIAS BibLIOGRÁfiCAS}

AUGUSTO, M. G. M. Discurso utópico e discurso mítico: um paralelo entre a República e o Timeu. Revista Filosófica Brasileira. Platão. Rio de Janeiro, IV (3), p. 91-101, dez., 1988. 
BRAGUE, R. Le Timée. In: . Le restant. Paris: Les Belles Lettres, 1978. p. 68-72.

BRISSON, L. Le Même et L'Autre dans la Structure Ontologique du Timée de Platon. Paris: Klincksiek, 1974. . Platon, les mots et les mythes. Paris: Maspero, 1982.

CONFORD, F.-M. Plato's cosmology. London: Routledge \& Kegan Paul, 1952.

COULOUBARITSIS, L. Mythe et Philosophie chez Parménide. Bruxelles: Ousia, 1986.

DETIENNE, M. L'invention de la mythologie. Paris: Gallimard, 1981.

. La double écriture de la mythologie: entre le Timée et le Critias. In: L'écriture d'Orphée. Paris: Gallimard, 1989. p. 167-86.

DIXSAUT, M. Le Naturel Philosophe. Essai sur les Dilogues de Platon. Paris: Les Belles Lettres, 1985.

FRUTIGER, P. Les mythes de Platon. Paris: Alcan, 1930.

MATTÉI, J.-F. L'étranger et le simulacre. Paris: PUF, 1983.

NIGHTINGALE, A. W. Genres in dialogue. Plato and the construct of philosophy. Cambridge: Cambridge University Press, 1996.

PLATON. Timée. Critias. Texte établi et traduit par A. Rivaud. 6 ed. Paris: Les Belles Lettres, 1985.

. Timée. Critias. Traduction de Luc Brisson. Paris: Flamarion, 1992.

ROSEN, S. Plato's Sophist. The drama of original and image. London: Yale University Press, 1983.

. The city as simulacrum. In: . Plato's Stateman. The web of politics. London: Yale University Press, 1995. p. 169-90.

VLASTOS, G. Socrates: ironist and moral philosopher. Cambridge: Cambridge University Press, 1991.

\section{INFORME}

Versão anterior e mais resumida deste texto apareceu em: Kleos. Revista de Filosofia Antiga. Rio de Janeiro, v. 1, p. 157-75, jul., 1997. 
SCHALCHER, Maria da Graça Ferreira. Le silence de Socrate dans l'exorde du Timée.

RÉSUMÉ: Dans ce texte nous essayons de comprendre les rapports entre le mythe et la philosophie dans la pensée de Platon, par le silence de Socrate dans le Timée.

MOTS-CLÉS: silence; mythe; philosophie; dialectique; histoire; temps; memoire; paradigme; imitation; ville; étranger; hospitalité. 